\title{
Observations of lunar tides in the mesosphere and lower thermosphere at Arctic and middle latitudes
}

\author{
D. J. Sandford, H. G. Muller, and N. J. Mitchell \\ Bath, BA2 7AY, UK \\ Received: 21 February 2006 - Published in Atmos. Chem. Phys. Discuss.: 12 June 2006 \\ Revised: 14 August 2006 - Accepted: 5 September 2006 - Published: 13 September 2006
}

Centre for Space, Atmospheric \& Oceanic Science, Department of Electronic and Electrical Engineering, University of Bath,

\begin{abstract}
Meteor radars have been used to measure the horizontal winds in the mesosphere and lower thermosphere over Castle Eaton $\left(52^{\circ} \mathrm{N}\right)$ in the UK and over Esrange $\left(68^{\circ} \mathrm{N}\right)$ in Arctic Sweden. We consider a 16-year data set covering the interval 1988-2004 for the UK and a 6-year data set covering the interval 1999-2005 for the Arctic. The signature of the 12.42-h $\left(\mathrm{M}_{2}\right)$ lunar tide has been identified at both locations. The lunar tide is observed to reach amplitudes as large as $11 \mathrm{~ms}^{-1}$. The Arctic radar has an interferometer and so allows investigation of the vertical structure of the lunar tide. At both locations the tide has maximum amplitudes in winter with a second autumnal maximum. The amplitude is found to increase with height over the $80-100 \mathrm{~km}$ height range observed. Vertical wavelengths are very variable, ranging from about $15 \mathrm{~km}$ in summer to more than $60 \mathrm{~km}$ in winter. Comparisons with the Vial and Forbes (1994) model reveals generally good agreement, except in the case of the summer vertical wavelengths which are observed to be significantly shorter than predicted.
\end{abstract}

\section{Introduction}

The dynamics of the mesosphere and lower thermosphere (MLT region) are dominated by waves and tides most of which propagate to this region from sources at lower heights. The atmospheric tides are excited either thermally by solar heating or gravitationally by the lunar and solar gravitational fields. Solar thermal excitation produces the well-known 24-, 12- and 8-h tides that are conspicuous features of the MLT region. The Sun's gravitational field plays only a minor role in the generation of these tides.

In addition to the solar tides, there are also tides observed in the atmosphere that have periods related to the apparent

Correspondence to: D. J. Sandford

(d.j.sandford@bath.ac.uk) motion of the Moon around the Earth. It is believed that these lunar atmospheric tides are generated primarily as a result of the Moon's gravitational attraction on the lower, denser regions of the atmosphere (Stening and Vincent, 1989). However, the vertical motion of the oceans at the lower boundary of the atmosphere may also contribute to the generation of lunar tides (Stening and Jacobi, 2001). A fundamental difference between tides excited by Moon's gravitational field and those excited by solar heating is that in the lunar case the forcing can be precisely specified whereas in the solar case the time-varying distributions of ozone and water vapour result in a corresponding variation in the tidal forcing and contribute the high degree of tidal variability observed in the MLT region.

A comprehensive treatment of lunar tides in the atmosphere is given by Chapman and Lindzen (1970). In total, there are more than 30 different modes which make up the lunar tide, but most have insignificant amplitudes. Of those modes that do reach significant amplitudes, the 12.420$\mathrm{h}$ ( 1.9323 cycles per day) migrating $\mathrm{M}_{2}$ lunar semidiurnal tide is the most important and reaches the largest amplitudes. However, a few other lunar tidal modes may also reach detectable amplitude, including the $\mathrm{O}_{1}$ and $\mathrm{N}_{2}$ modes (Winch and Cunningham, 1972). The $\mathrm{O}_{1}$ is the diurnal component of the lunar tide and has a period of $24.878 \mathrm{~h}$ and has been observed in geomagnetic data, where it typically has an amplitude $\sim 40 \%$ of that of $\mathrm{M}_{2}$ tide (Stening and Vincent, 1989). The 12.658-h $\mathrm{N}_{2}$ tide occurs at a very similar frequency to that of the $\mathrm{M}_{2}$ tide and arises from the elliptical orbit of the Moon which varies the lunar distance from the Earth over a period of a month. The $\mathrm{N}_{2}$ tide has been suggested to have an amplitude $\sim 19 \%$ of that of the $\mathrm{M}_{2}$ tide (Schlapp et al., 1996). These smaller amplitude lunar tides are close to the limit of what can be detected in mesospheric wind data and so will not be considered further. Instead, we will focus our interest on the 12.420-h $\mathrm{M}_{2}$ lunar tide.

Published by Copernicus GmbH on behalf of the European Geosciences Union. 


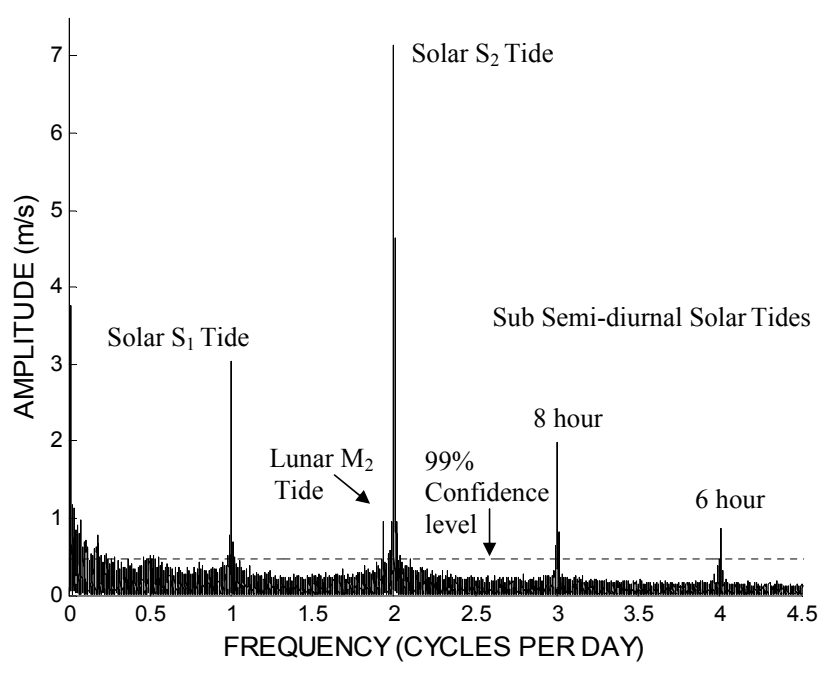

Fig. 1a. Lomb-Scargle analysis of zonal horizontal wind data over an interval of 16 years (1988-2004) from the UK meteor radar.

Lunar tides in the atmosphere have proved difficult to study because of their comparatively small amplitudes when compared to the solar tides. In the MLT region, lunar tides are thought to seldom reach amplitudes of more than $\sim 10 \mathrm{~ms}^{-1}$. Further, because their frequencies are close to those of the solar tides, extended data sets are required to provide the necessary spectral resolution to distinguish solar and lunar components.

Despite the difficulty in identifying lunar tidal signatures in the MLT region, a number of studies have detected their presence. These studies have invariably relied on long data sets of up to $\sim 13$ years duration. Various techniques have been used, including MF radar (e.g., Stening et al., 1987, 1994), MST radar (e.g., Stening et al., 1990), meteor radar (e.g., Tsuda et al., 1981; Stening et al., 2003) and LF-D1 (Stening and Jacobi, 2001). In general, these studies have revealed lunar tides to have a distinct seasonal cycle, with maximum amplitudes usually occurring around midwinter and autumn in the northern hemisphere. Vertical wavelengths are observed to be quite short, ranging from $\sim 17 \mathrm{~km}$ to $\sim 80 \mathrm{~km}$.

A very limited number of modelling studies have addressed lunar tides in the atmosphere. Vial and Forbes (1994) considered the seasonal variability of the $\mathrm{M}_{2}$ mode from the ground to a height of $105 \mathrm{~km}$. It is a zonal mean model showing the latitudinal variations. At meteor heights, amplitudes were predicted to reach up to $\sim 10 \mathrm{~ms}^{-1}$.

In the work presented here, observations of the $\mathrm{M}_{2}$ lunar tide made with two meteor radars are reported. One radar is at middle latitudes, the other in the Arctic. Data from several years are investigated to establish the seasonal variability of the tide and to determine its vertical structure at Arctic latitudes.

\section{Data analysis}

The data used in this study have been collected from two meteor radars - one at Castle Eaton $\left(52.6^{\circ} \mathrm{N}, 2.19^{\circ} \mathrm{W}\right)$ in the UK and the other at Esrange $\left(67.9^{\circ} \mathrm{N}, 21.1^{\circ} \mathrm{E}\right)$ in Arctic Sweden. The UK radar is a narrow beam system using two orthogonal beams operating at $36.75 \mathrm{MHz}$. This radar has been in near-continuous operation since January 1988 (although with a one-year gap in 1995-1996 when only one beam was used). Horizontal wind components measured in the two beams are combined to give hourly-spaced estimates of the zonal and meridional wind. The data set considered here did not include an estimate of the heights of individual meteors, so the winds are representative of the MLTregion, weighted by the vertical distribution of meteor echoes at the radar's operating frequency. A description of the Castle Eaton radar is given in Muller et al. (1995) and Beldon et al. (2006).

The Esrange radar has been described by Mitchell et al. (2002). It is a SKiYMET, all-sky system with a transmitter frequency of $32.5 \mathrm{MHz}$. Continuous data has been recorded from October 1999 with no significant gaps. The radar uses a set of five receiving antennas as an interferometer to determine the meteor trail azimuth and zenith angles, which in combination with range information allows the determination of echo height. Routine range resolution is $\sim 2 \mathrm{~km}$. If the reader refers to Fig. 3 in Mitchell et al. (2002) it is seen that the height distribution of meteors using a radar of $32.5 \mathrm{MHz}$, is strongly peaked at $\sim 90 \mathrm{~km}$ with only very weak seasonal variation. Therefore the winds derived from the UK meteor radar, using the slightly higher frequency of $36.75 \mathrm{MHz}$ are also likely to be centred at $90 \mathrm{~km}$.

The first question to be addressed is this: is a lunar tidal signal detectable in the data set at all? To answer this question, a Lomb-Scargle analysis was applied to the 16-year UK data set. The results of this analysis are presented in Fig. 1a. The figure shows very clear responses at periods of 24-, 12-, 8- and 6-h corresponding to the solar tides. A confidence level of $99 \%$ is indicated. The tidal amplitudes are relatively small, of order only a few $\mathrm{ms}^{-1}$, because of phase cancellation resulting from the seasonal changes in phase of the tides. We should also note that the presence of strong, deterministic signals in the time series (in this case the tides themselves) has the effect of making the confidence level somewhat pessimistic. The figure also shows a clear response at the period of the $\mathrm{M}_{2}$ lunar tide. Note that the 6-h and 8-h tides over Esrange have been described elsewhere (Smith et al., 2004; Younger et al., 2002; Beldon et al., 2006).

Figure $1 \mathrm{~b}$ shows an expanded view of the periodogram of Fig. $1 \mathrm{a}$ for frequencies near that of the $\mathrm{M}_{2}$ lunar tide. The figure shows that, in fact, two closely spaced peaks are present near the $\mathrm{M}_{2}$ frequency and are of approximately equal amplitude. The frequencies of these peaks are $\sim 1.9323$ and 1.9350 cycles/day. The first of these corresponds exactly to the $\mathrm{M}_{2}$ lunar frequency (as near as can be determined by the 


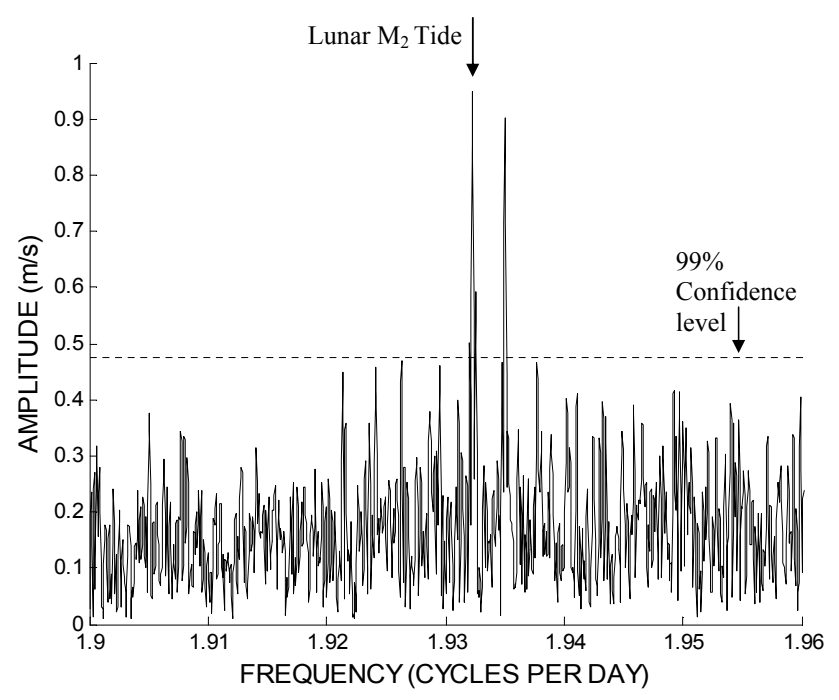

Fig. 1b. A zoomed in view of the Lomb-Scargle periodogram shown in Fig. 1a, shows a peak at the frequency corresponding to the $\mathrm{M}_{2}$ lunar tide.

available spectral resolution). We will take this peak to be strong evidence of a lunar tide being present in the dataset. The second peak corresponds to an oscillation which has almost exactly one more complete cycle per year. An explanation for this observation will be considered in Sect. 4. A similar analysis applied to the Esrange radar dataset yields similar results (not shown).

A second indication that a lunar tide has been detected is provided by a superposed epoch or "composite lunar day" analysis. Because the lunar tides are "Moon following" rather than "Sun following", they will not repeat from day to day with the same phase as measured in local time. Instead, an analysis must be applied that relates the tidal phase to the position of the Moon in the sky. In this case, zonal and meridional winds were sorted by lunar time (one lunar day is defined as $24 \mathrm{~h} 50 \mathrm{~min}$ : the time it takes for the Moon to make one complete orbit of the Earth) and averaged over extended intervals. An example is given in Figs. 2a, b which presents composite lunar day analyses of data recorded over Esrange from the three-month interval December 2000-February 2001. Figure 2a represents the zonal (east - west) component and Fig. $2 b$ the meridional (north - south) component. The composite day analysis reveals only features that have an integer number of cycles in a lunar day of $24.84 \mathrm{~h}$. In this case, a clear lunar semidiurnal tide is apparent. The amplitudes reach values as large as $\sim 10 \mathrm{~ms}^{-1}$. A clear phase progression is also evident. We take this as further evidence that a significant lunar tide is present and can be identified in the data.

Studies by other authors have investigated a number of different methods of isolating the lunar tide from time series of geophysical data. Stening et al. (1997b) compared least-

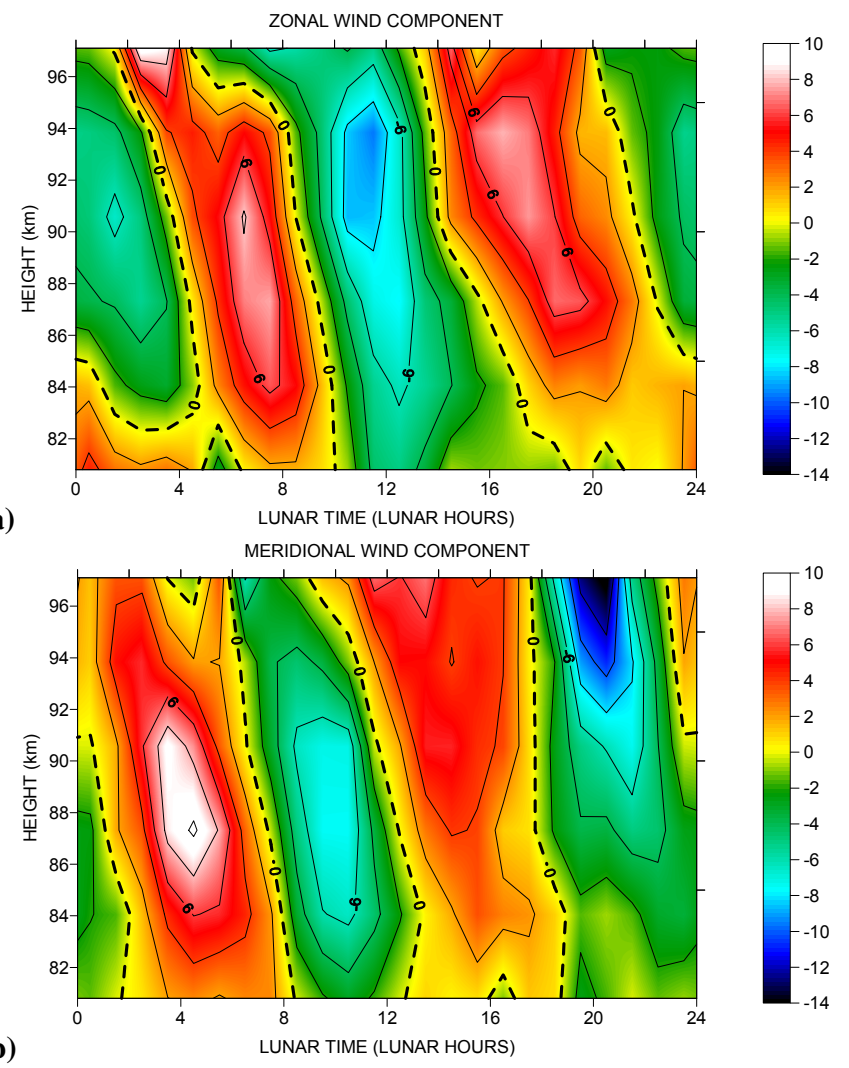

Fig. 2. Composite lunar day of zonal (a) and meridional (b) horizontal wind data for winter (DJF) 2000/2001 over Esrange (1 Lunar day $=24$ Lunar hours $=24.84$ Solar hours).

squares fitting of a sum of solar and lunar tides to geophysical time series (Malin and Schlapp, 1980) in comparison to methods based on Fourier analysis (Winch and Cunningham, 1972) and concluded that the least-squares method offers a number of advantages. In particular, each hourly data point is treated separately, so scattered and/or missing data is not a problem. Further, with this method results can be accurately tuned to the required tidal frequencies.

In the work presented here, the analysis follows the technique of Stening et al. (1997b). The time series of zonal or meridional horizontal winds, $u, v(t)$, was taken to consist of a superposition of a number of tidal oscillations. The a priori assumption was made that these tides are sinusoidal, have periods of 24-, 12-, 8-, 6- and 12.420-h and arbitrary phases and amplitudes, corresponding to the first four principle solar tides and the $\mathrm{M}_{2}$ lunar tide, as per Eq. (1).

$u, v(t)=\bar{u}, \bar{v}+\sum A(\omega) \cdot \cos \left[\frac{2 \cdot \pi \cdot \omega \cdot t}{24}-\theta(\omega)\right]$

Where $\bar{u}$ or $\bar{v}$ is the mean wind, A is the amplitude of a particular tide, $\theta$ is its phase, $t$ is the time step in hours and $\omega$ is its frequency in cycles per day. 


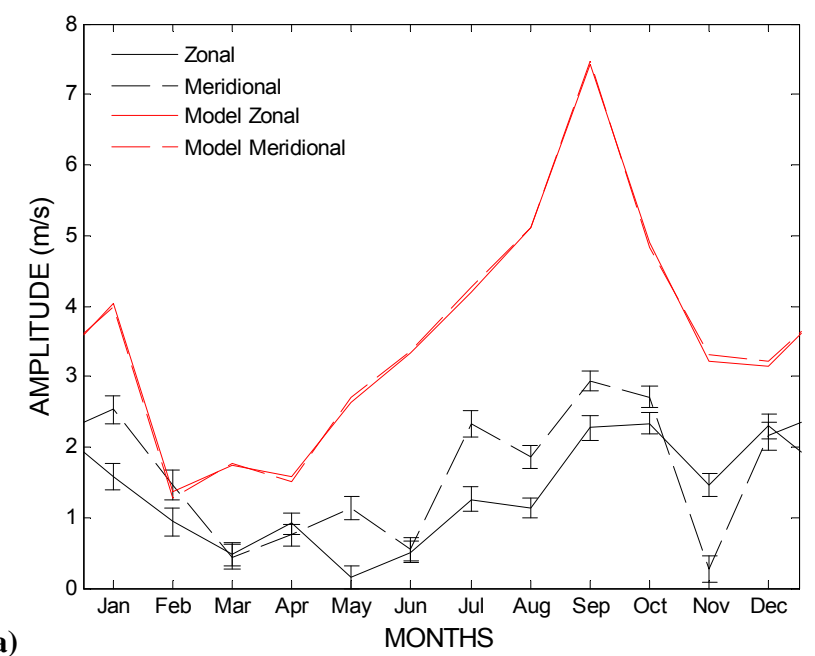

(a)

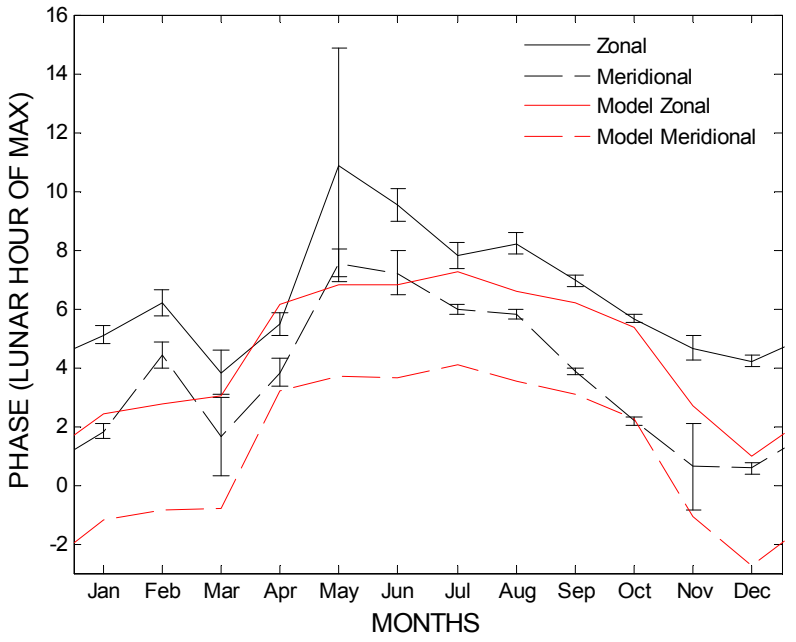

Fig. 3. Monthly-mean amplitudes (a) and phases (b) of the Lunar $\mathrm{M}_{2}$ tide calculated from UK data (1988-2004) vector averaged to produce the seasonal variation indicated in black. Red lines indicate model amplitude results from Vial and Forbes (1994) model. Solid lines represent the zonal component and dashed the meridional component. Error bars indicate the standard error on the mean.

The time series of horizontal winds were then analysed in segments to determine the amplitude and phase of each tidal component for that particular time series segment. Investigation showed that a dataset length of $>15$ days was necessary in order to resolve the lunar $\mathrm{M}_{2}$ tide from the solar $\mathrm{S}_{2}$ tide because they are closely spaced in frequency (a similar conclusion follows from sampling theory).

In light of this result, the analysis was performed using one-month segments of data. This approach has the additional advantage of allowing easy comparison to other observations and to the monthly-mean results from the model of Vial and Forbes, 1994 - in Sects. 3 and 4. In the case of the Esrange radar, the analysis was applied to winds calculated in six height gates. The height gates used have depths of 5, 3, 3, 3,3 and $5 \mathrm{~km}$ (from 78-100 km). Because of the uneven ver- tical distribution of meteor echoes, which is strongly peaked at $\sim 90 \mathrm{~km}$, the winds calculated for each height gate are assigned to the average meteor echo height for that gate. This leads to the winds being calculated at representative heights of $81.1,84.6,87.5,90.4,93.3$ and $96.8 \mathrm{~km}$. Note that each height gate is independent of the others.

A key difference between the solar and lunar tides is that the former are Sun following, and so (allowing for seasonal variations) the tide has a phase that is consistent in local time from day to day. In contrast, the lunar tides are Moon following, and so the phase will decrease systematically from day to day when measured in local solar time. Lunar tidal phases must therefore be measured with respect to the position of the Moon.

The main term in the gravitational potential generating the lunar $\mathrm{M}_{2}$ tide varies as $\cos (2 \tau)$, where $\tau$ is know as the "lunar time" and is given by $\tau=t-v$, where $t$ is the local solar time and $v$ is the lunar age, which is a measure of the phase of the Moon and where $v=0$ signifies new moon (Stening et al., 1987; Stening and Vincent, 1989). Consequently, lunar tidal phases are measured with respect to the time of the last new Moon. Also, note that because of the approximate semidiurnal nature of the lunar tide, all phases can be arbitrarily shifted by 12 lunar hours.

\section{Results}

\subsection{Mid-latitude seasonal behaviour}

Monthly-means of amplitude and phase were calculated for tides of period 24-, 12-, 8-, 6- and 12.420-h in all of the months available in the 16 years of the UK data set. The monthly-means of amplitude and phase for the $\mathrm{M}_{2}$ lunar tide for each month from successive years were then vector averaged to reveal the seasonal variability. Figure $3 \mathrm{a}$ presents the vector-averaged monthly-mean amplitudes for the zonal and meridional components. The error bars indicate the standard error on the mean. Also indicated are the monthlymean amplitudes from the Vial and Forbes (1994) model for a height of $93 \mathrm{~km}$ (selected as being the height closest to that of the meteor-radar observations). The figure shows that the observed zonal and meridional amplitudes are generally quite close and that a clear seasonal cycle is apparent in which largest amplitudes are observed in winter (JanuaryFebruary) and autumn (September-October). Amplitudes reach an extended minimum throughout the spring and summer months (March-August). A distinct drop in amplitudes is evident in November, following the autumnal maximum and before the amplitudes rise in winter.

A comparison with the model shows that it captures the observed general seasonal behaviour quite well, although the model amplitudes are significantly higher - maximising at some $\sim 8 \mathrm{~ms}^{-1}$ in September compared to the observed $\sim 2-3 \mathrm{~ms}^{-1}$. We should note, however, that at meteor heights 
the model amplitudes increase rapidly with height and so small height differences result in better or worse agreement.

Figure $3 \mathrm{~b}$ presents the observed vector-averaged monthlymean phases for the zonal and meridional components over the 16 years of data. A systematic phase difference of $\sim 3.14$ lunar hours $\left(\sim 91^{\circ}\right)$ between the components, when the amplitude is high, is evident and a systematic phase difference of $\sim 2.77$ lunar hours $\left(\sim 80.2^{\circ}\right)$ if all months are considered. These values in combination with the approximately equal zonal and meridional amplitudes correspond to an approximately circularly-polarised oscillation in which the wind vector rotates in a clockwise manner and for the northern hemisphere, indicates an upwardly propagating tide.

The phases themselves show a clear seasonal cycle. The phases have the smallest values in winter and early spring (December-March), they advance rapidly by some $\sim 6$ lunar hours in late-spring to early summer (April-May) and then decline at a fairly constant rate throughout the summer and autumn back to the winter values. Also indicated in the figure are the corresponding phases from the Vial and Forbes model for a model height of $93 \mathrm{~km}$. In comparison to the observations, it can be seen that the model reproduces the seasonal behaviour well, but that there is a systematic phase difference in which the model phases lead the observed phases by $\mathrm{a} \sim 2.12$ lunar hours.

\subsection{Mid-latitude inter-annual behaviour}

Finally, we should note that the figures indicate that the $\mathrm{M}_{2}$ lunar tide exhibits a high degree of inter-annual variability in both amplitude and phase. The standard deviations of the amplitudes and phases are significant, being $\sim 4$ times larger than the standard errors indicated. The phase fluctuations mean that there is some degree of cancellation in the vectoraveraging of the amplitudes, and it was found that geometric averaging of the amplitudes resulted in averaged monthly means some $\sim 72 \%$ larger.

To further investigate this inter-annual variability, Fig. 4 presents the annual (geometric) mean of the tidal amplitude for the interval 1988-2005, separated into the four seasons. To simplify the figures, the zonal and meridional amplitudes are averaged together. The gap in the data from March 1995 to December 1996 when only one beam of the radar was operating is filled using measurements made in that beam only. The figures show that there is considerable year-toyear variability in seasonal-mean amplitudes, which vary by more than a factor of two from year to year.

\subsection{Arctic seasonal behaviour}

A similar analysis to that performed with the UK data was applied to data recorded by the Esrange meteor radar - although in this case six independent height gates were available between 80 and $100 \mathrm{~km}$, allowing an investigation of the vertical structure of the tide.
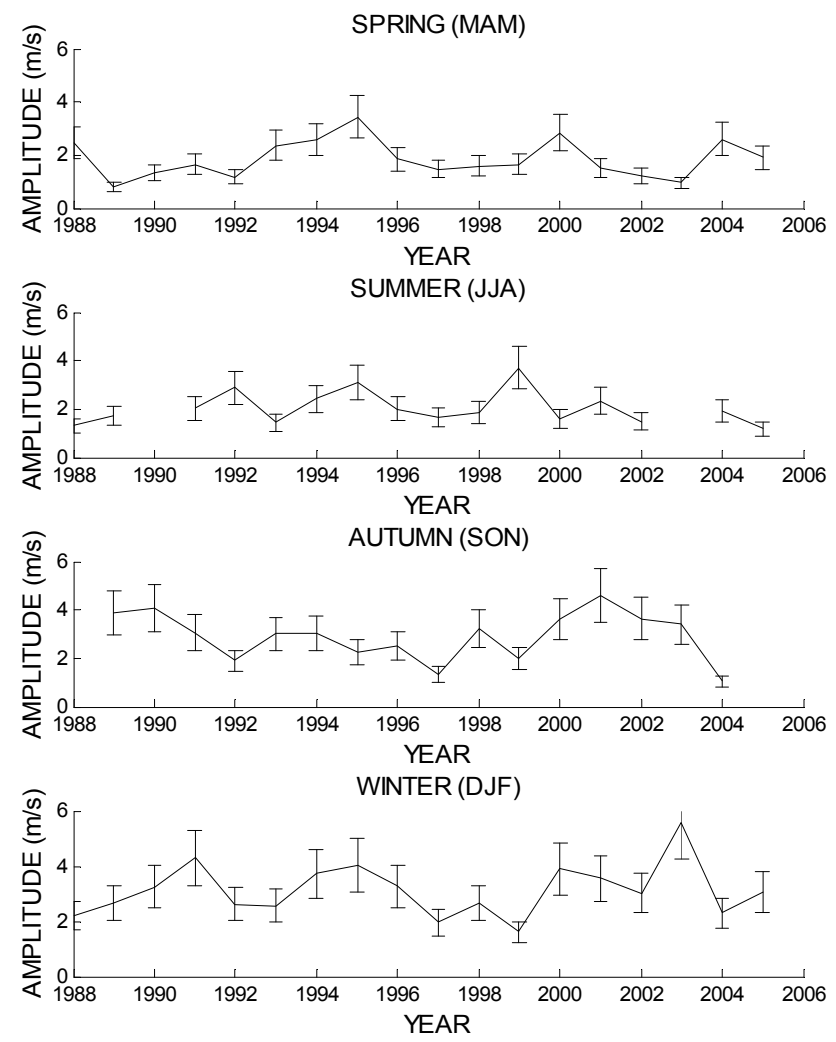

Fig. 4. Year to year variability of the Lunar $M_{2}$ tidal amplitude calculated using monthly - mean amplitudes of the zonal UK data (1988-2004) averaged in to seasons. Error bars indicate the standard error on the mean.

Figures 5a, b present contours of the amplitude of the zonal and meridional components of the $\mathbf{M}_{2}$ lunar tide. As before, the data have been vector averaged to produce a composite year from the six years of data available (October 1999-October 2005).

Both sets of contours reveal a generally similar and welldefined seasonal behaviour in which the largest amplitudes of $\sim 8 \mathrm{~ms}^{-1}$ are reached for a month in winter (DecemberFebruary) and in which there is a secondary maximum around August-September. Amplitudes are generally small and relatively constant $\left(<2 \mathrm{~ms}^{-1}\right)$ during an extended minimum occurring throughout the spring and summer months (March-July). Except at the lowest heights, the ratio of maximum to minimum monthly-mean amplitudes is larger than over the UK. Amplitudes rise with increasing height in all months (except in September where a localised amplitude maximum occurs near $87 \mathrm{~km}$ ). The small reduction in amplitudes evident in November in the UK data (Fig. 3a) also has a counterpart in the amplitude minimum observed during October-November in the Arctic.

These results from the Arctic are now compared with the Vial and Forbes (1994) model. Figure 6 presents height profiles of amplitude for each month in which the Esrange 
Table 1. Monthly-mean vertical wavelengths observed over Esrange (68 N, 21 E) in October 1999 to December 2005 and those from the model of Vial and Forbes (1994). The wavelengths are calculated over the height range $80-100 \mathrm{~km}$ and zonal and meridional values averaged.

\begin{tabular}{lll}
\hline Month & Measured Vertical Wavelength $(\mathrm{km})$ & Vertical Wavelength $(\mathrm{km})$ from the model of Vial and Forbes $(1994)$ \\
\hline January & $63(+/-6)$ & $42(+/-16)$ \\
February & $33(+/-6)$ & $14(+/-2)$ \\
March & $15(+/-2)$ & $14(+/-1)$ \\
April & $26(+/-10)$ & $14(+/-5)$ \\
May & $27(+/-11)$ & $-149(+/-75)$ \\
June & $15(+/-1)$ & $-121(+/-31)$ \\
July & $36(+/-26)$ & $-80(+/-44)$ \\
August & $47(+/-18)$ & $189(+/-42)$ \\
September & $48(+/-9)$ & $57(+/-3)$ \\
October & $22(+/-3)$ & $35(+/-1)$ \\
November & $18(+/-7)$ & $23(+/-15)$ \\
December & $44(+/-1)$ & $27(+/-17)$ \\
\hline
\end{tabular}

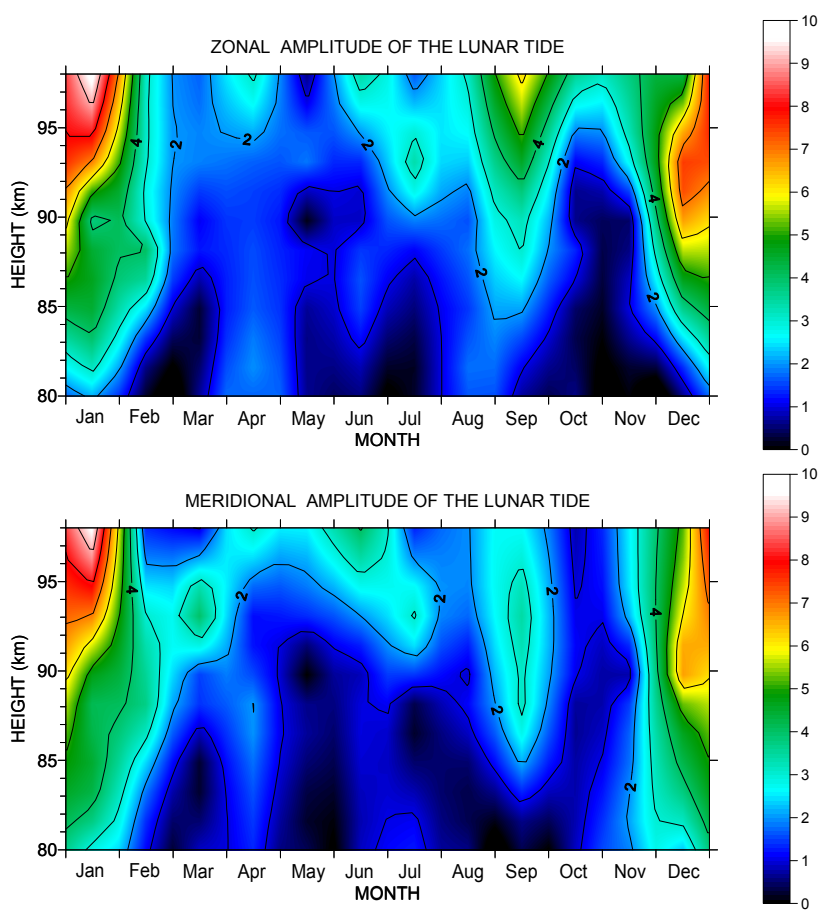

Fig. 5. Contour plot of the Lunar $\mathrm{M}_{2}$ tidal amplitude calculated from monthly-mean amplitudes (vector averaged to give the seasonal variation) of zonal and meridional wind data over the period 1999-2005 from the Esrange meteor radar. Colour scale indicates amplitude.

observations are plotted along with the predictions of the model. Both the zonal and meridional components are plotted. In most months the model amplitudes agree well with the observations (i.e., within a few $\mathrm{ms}^{-1}$ ). However, from the autumnal equinox to early winter (September to November) the observed amplitudes are systematically smaller than those of the model. For instance, in October the model predicts a rapid growth of amplitude with height to amplitudes of $>5 \mathrm{~ms}^{-1}$ at heights above $90 \mathrm{~km}$. The observations reveal very limited growth of amplitude, with amplitudes $<2 \mathrm{~ms}^{-1}$ below $\sim 95 \mathrm{~km}$. In contrast, during December-January, the observations reveal amplitudes below $\sim 90 \mathrm{~km}$ that are significantly larger than predicted. For instance, in December, the rapid growth of amplitude with height occurs rather lower than in the model. In summary, the observations reveal smaller amplitudes than predicted in autumn and early winter, and larger amplitudes than predicted around the winter solstice.

Figure 7 presents a similar analysis applied to the phases. Again, both the zonal and meridional components of the observed and model tides are presented as vector averages of data over the six years observed. The phase indicates the hour of maximum wind in the eastward direction. Generally, the phase behaviour shows the meridional component leading the zonal by $\sim 3$ lunar hours, corresponding to phase quadrature and a wind vector which rotates clockwise in time (when viewed from above) - corresponding to an upwardlypropagating tide. Error bars are not shown in the figure for reasons of clarity. However, the mean uncertainty (error on the mean) in phase over the entire ensemble of monthly data is 0.9 lunar hours. The uncertainty in phase is largest when the amplitudes are smallest. The largest uncertainties occurred in October, when the average error bar has a value of $\sim 3.3$ lunar hours. The smallest uncertainties occurred in January, when the average error bar has a value of $\sim 0.3$ lunar hours.

It is noticeable that when the amplitudes are large (e.g., in September, December and January) the phase progression of the tide with height is very smooth. This regular progression of phase and consistent phase quadrature over the six independent height gates observed provides further confidence that a clear tidal signature has been identified. 

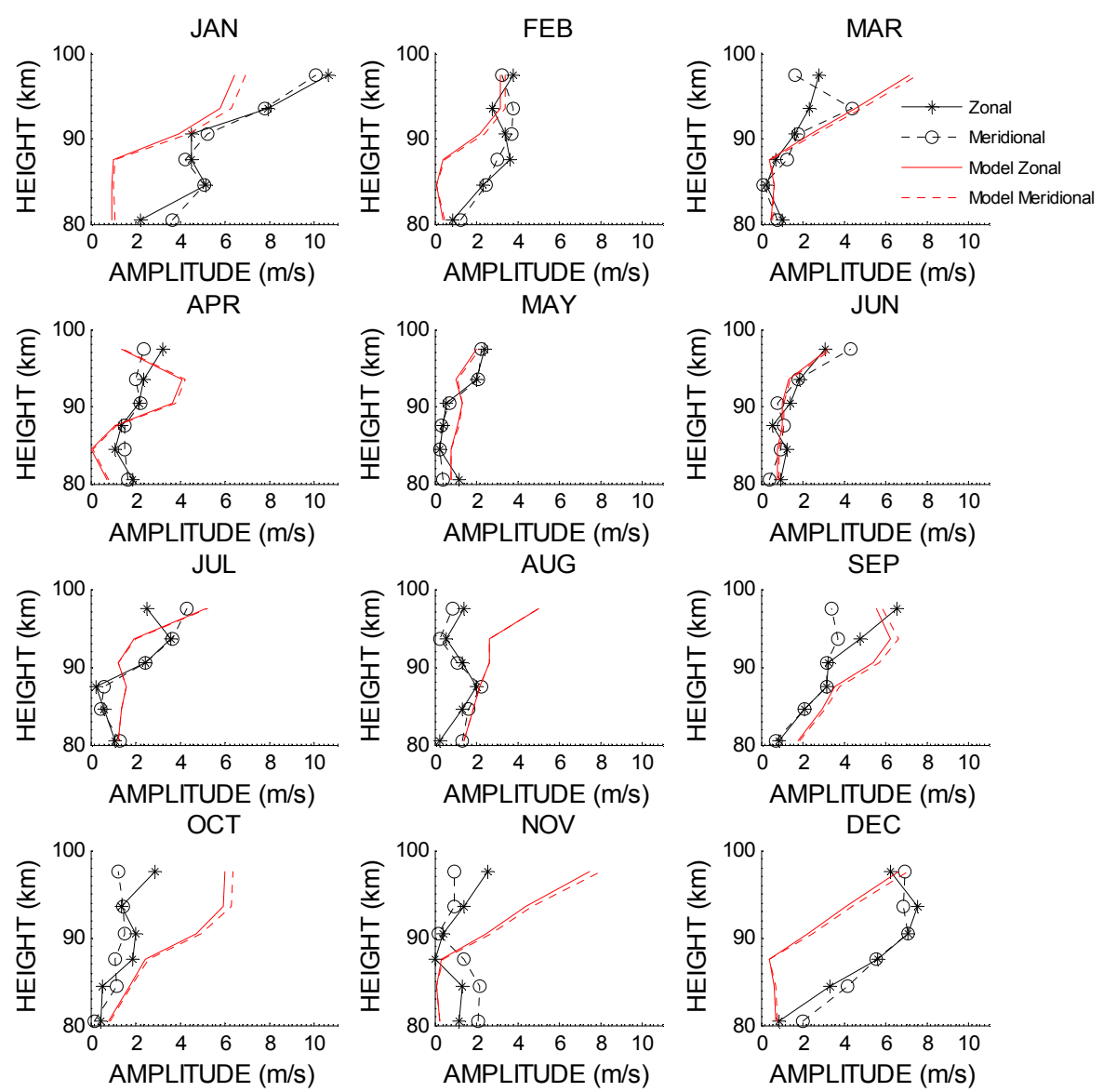

Fig. 6. Monthly amplitude plots of the Lunar $\mathrm{M}_{2}$ tide over Esrange. Black symbols indicate tidal amplitudes calculated from the Esrange meteor radar over the period 1999-2005 and the red lines indicate results from the Vial and Forbes (1994) model. Solid lines show the zonal (stars) component and dashed show the meridional (circles).

The variation of tidal phase with height allows calculation of the vertical wavelength for each month. Table 1 lists the observed vertical wavelengths and those from the model of Vial and Forbes (1994). The vertical wavelengths are an average of the zonal and meridional components. Phases with the largest errors (i.e. those with the smallest amplitudes) have been excluded from the vertical wavelength determination, but are still shown in Figs. 6 and 7. In general, the observations match reasonably with the modelled results, with larger values in winter and summer, and smaller values in spring and autumn. Towards the end of spring and summer, the modelled phase sometimes increases with altitude, resulting in a negative vertical wavelength.

Finally, note that the inferred vertical wavelengths are derived from the $\sim 20 \mathrm{~km}$ height range, which is often only a small fraction of the wavelength. The results therefore should be regarded as representing a localised vertical wavelength, rather than implying a vertical wavelength existing over a large height range.

At times when the amplitudes are small (particularly during the spring and early summer months) the phase estimates are less reliable. To clarify the behaviour of the phases during these times, seasonal-mean phases were calculated. The seasonal-mean phases are shown in Fig. 8, as are the seasonal means from the model. Comparing the observations to the model phases, it can be seen that agreement is excellent in autumn and winter (differences $<2 \mathrm{~h}$ ) and quite good in spring with a phase shift of $\sim 7 \mathrm{~h}$ with the observations leading the model (which is also equivalent to a shift of $5 \mathrm{~h}$ on the next phase track with the observations lagging behind the model). Significant differences occur in summer where the seasonal-mean observations have a much shorter vertical wavelength, than the near vertical modelled ones.

\section{Discussion}

We have argued that a clear signature of the $\mathrm{M}_{2}$ lunar tide is evident in meteor-radar observations of the mid-latitude and Arctic MLT region. In Sect. 2 we noted that the periodogram of Fig. 1b actually displays two peaks at frequencies of $\sim 1.9323$ and 1.9350 cycles/day. The first of these is 

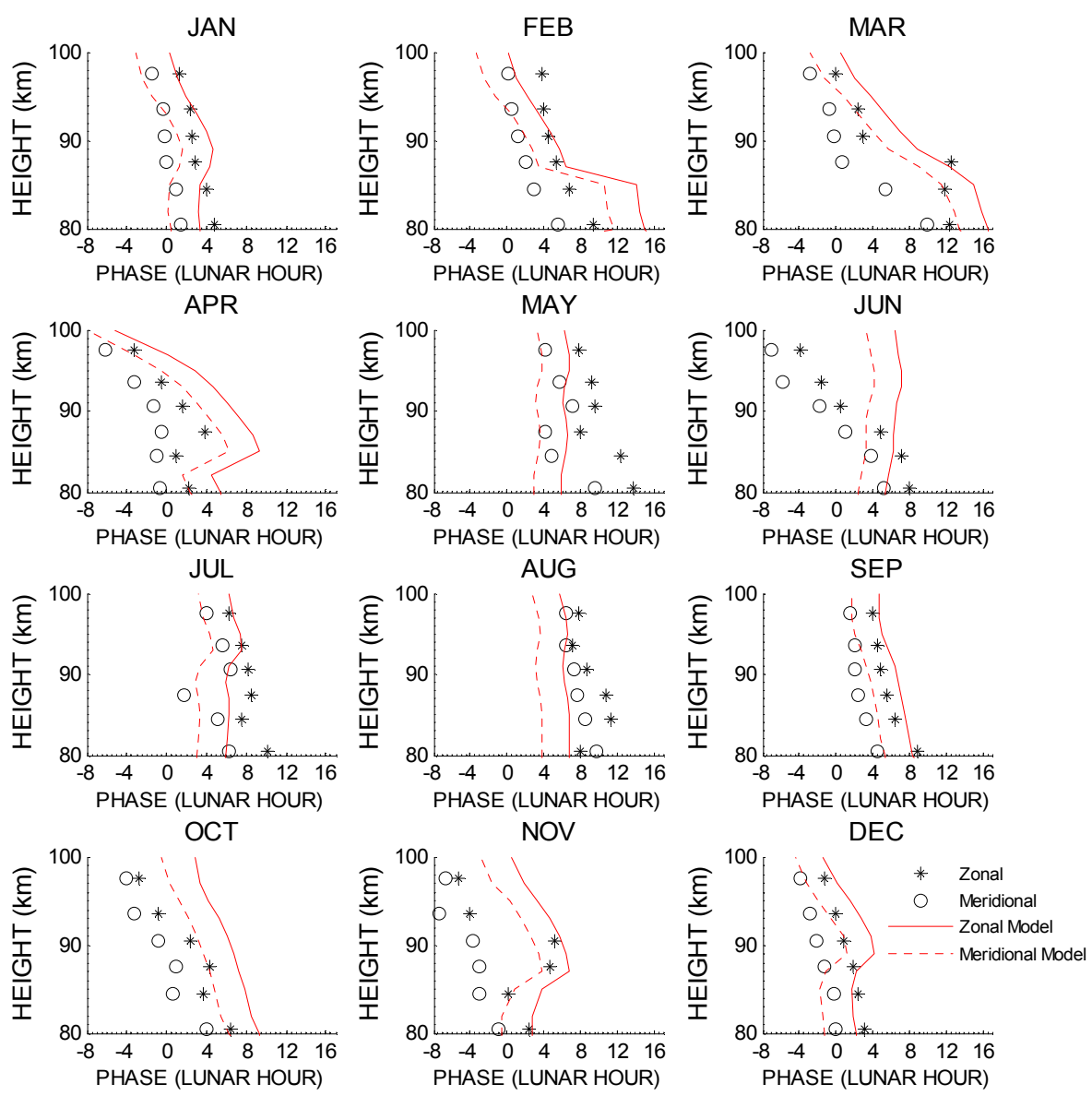

Fig. 7. Monthly phase plots of the Lunar $\mathrm{M}_{2}$ tide over Esrange. Black symbols indicate tidal phases calculated from the Esrange meteor radar over the period 1999-2005 and the red lines indicate results from the Vial and Forbes (1994) model. Solid lines show the zonal (stars) component and dashed show the meridional (circles).

the $\mathrm{M}_{2}$ lunar period. The second can be explained as a result of the response of the periodogram to a non-stationary time series (i.e., one in which the amplitude and phase of the $\mathrm{M}_{2}$ oscillation vary over the course of the year). The seasonal cycle in $\mathrm{M}_{2}$ tidal amplitude (large amplitudes in winter, small amplitudes in summer) is interpreted by the periodogram analysis as the result of a beating between two closely-spaced frequencies. Since the amplitude varies with an annual cycle, the periodogram represents this as two oscillations, spaced in frequency such that one has one more cycle per year than the other. The difference in frequency between these oscillations is thus $1 / 365$ cycles per day, which is $\sim 0.00274$ cycles/day - the difference in frequency between the two peaks observed in Fig. 1b. We therefore conclude that the two peaks in this figure in fact, represent the response of the periodogram to the seasonally-varying $\mathrm{M}_{2}$ lunar tide, and not two independent oscillations.

A comparatively small number of studies have reported observations of the lunar semidiurnal tide in the MLT region. The small amplitude of the tide makes it difficult to study and there appears to be a high degree of inter-annual variability.
Considering first the middle latitudes, Stening and Jacobi (2001) reported LF-D1 observations made over Collm $\left(52^{\circ} \mathrm{N}, 15^{\circ} \mathrm{E}\right)$ during the 12-year interval $1985-1997$. The location of Collm differs in longitude by $17^{\circ}$ from the UK. This difference is accounted for using the analysis method described by Malin and Schlapp (1980) (i.e. the phases, time of maximum, should be directly comparable for the migrating lunar tide). They describe their measurements as being representative of the height range $\sim 90-100 \mathrm{~km}$. The monthly-mean amplitudes agree well with those measured here by meteor radar. A similar seasonal behaviour is apparent with good agreement for the amplitudes. The phases again have a generally similar seasonal pattern, but the phases show a systematic difference of $\sim 2$ lunar hours, with the Collm data leading the UK data. This difference most likely reflects the slightly different height ranges observed by the two techniques.

Observations made by MF radar over Saskatoon $\left(52^{\circ} \mathrm{N}\right.$, $107^{\circ} \mathrm{W}$ ) in 1987-1988 were reported by Stening et al. (1994). The seasonal behaviour of the tidal amplitude was similar to that observed over the UK and reported here, 
however the amplitudes over Saskatoon were $~ 50 \%$ larger than over the UK. The Saskatoon results were obtained at a height of $99 \mathrm{~km}$, higher than the representative meteor height of $\sim 90 \mathrm{~km}$ considered here. There is also a known discrepancy with MF radar measurements over $\sim 94 \mathrm{~km}$ where the measurements are influenced by group retardation effects, resulting in less reliable data. So this again this may explain the difference. We should also note that the high degree of interannual variability may lead to significant differences when only a few years of data are compared. Even considering this, the phases do generally agree to within $\sim 2$ lunar hours.

At Arctic latitudes, Stening et al. (1990) reported observations made over Poker Flat $\left(65^{\circ} \mathrm{N}, 147^{\circ} \mathrm{W}\right)$ using an MST radar in meteor mode in 1983-1984. The monthly-mean amplitudes observed agree very well with those observed over Esrange, except in spring, when the Poker Flat amplitudes are large compared to those over Esrange $\left(\sim 3-5 \mathrm{~ms}^{-1}\right.$ over Poker Flat c.f. $\sim 1 \mathrm{~ms}^{-1}$ over Esrange). As before, the relatively short duration of observations at Poker Flat means that it is not clear if this is a systematic difference of a result of inter-annual variability.

Stening et al. (1990), also report tidal phases at heights of 90 and $103 \mathrm{~km}$ over Poker Flat. Comparing their phases for $90 \mathrm{~km}$ to those observed at the same height over Esrange, the phases are generally in good agreement from September-December, with the difference being less than $\sim 2$ lunar hours. However, significant differences exist in summer (June-August) and winter/spring (January-April), when the difference is $\sim 6$ lunar hours (i.e., the tides are effectively in anti-phase over the two sites).

Stening et al. (1990) also reported monthly-mean vertical wavelengths over Poker Flat for the months of March, July, September and December measured over the interval 1980-1984. Not all years produced useable data for each month. In March, one year of observations suggested a vertical wavelength of $\sim 17 \mathrm{~km}$ (c.f. the Esrange six-year mean of $\sim 15 \pm 2 \mathrm{~km}$ ). In July a five-year mean was $\sim 90 \mathrm{~km}$ (Esrange six-year mean $\sim 36 \pm 26 \mathrm{~km}$ ), in September a two-year mean was $\sim 51 \mathrm{~km}$ (Esrange six-year mean $\sim 48 \pm 9 \mathrm{~km}$ ) and in December a one-year mean was $\sim 29 \mathrm{~km}$ (Esrange sixyear mean $\sim 44 \pm 1 \mathrm{~km}$ ). The agreement between observations over Esrange and Poker Flat is thus excellent in March and September, but in July the vertical wavelength over Esrange is significantly shorter than over Poker Flat. In December, it is significantly longer.

Some of the interannual variability can be accounted for by the influence of the underlying stratospheric winds (Stening et al., 1997a). However, the small amplitude of the lunar tide in the MLT region effectively limits our study to monthlymean properties and prevents the detailed investigation of the effects of stratospheric warmings etc. Nevertheless observations of the conjugate latitude in Antarctica may show different variability because of the lack of regular major sudden stratospheric warmings.
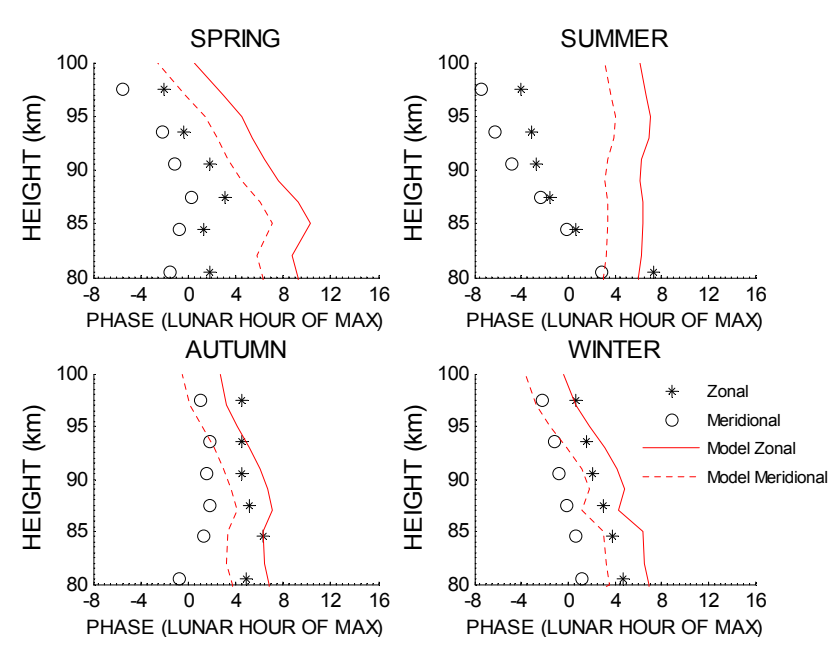

Fig. 8. Seasonal phase plots of the Lunar $\mathrm{M}_{2}$ tide over Esrange. Black symbols indicate tidal phases calculated from the Esrange meteor radar over the period 1999-2005 and the red lines indicate results from the Vial and Forbes (1994) model. Solid lines show the zonal (stars) component and dashed show the meridional (circles).

An interesting result is the strong similarity of the seasonal behaviour of the $\mathrm{M}_{2}$ lunar tide reported here and the solar 12-h $\mathrm{S}_{2}$ observed over Esrange and reported by Mitchell et al. (2002). Both tides have strong amplitude maxima in winter and brief secondary maxima in September. Such similarity may simply reflect the very similar propagation environments encountered by the lunar and solar tides which are very close in frequency and global-scale structure. Possible causes of this seasonal variability in the $S_{2}$ solar tide have been discussed by Riggin et al. (2003) - including refractive effects caused by shears in the mean zonal wind and gradients in temperature. Given the similarity between the solar and lunar tide, it is likely that propagation conditions, rather than source variations, are the mechanisms that produces the variability observed in the tides; if the propagation conditions are the source of the variability, then they are likely to affect the solar and lunar migrating tides in similar ways, but if source variations (e.g. concentrations of ozone or water vapour) are the cause of semidiurnal solar tidal variation, then seasonal variations are likely to differ.

It should also be noted that seasonal variation of the semidiurnal tide at high latitude is likely to be partly due to the combination of non-migrating modes. An example of non-migrating solar semidiurnal tidal components in the southern hemisphere at high latitudes is given by Murphy et al. (2003).

An important consequence of the significant amplitudes reached by the lunar tide in the MLT region may be in the interpretation of tidal variability. Quasi-periodic variations in the amplitude of tides are often taken to result from nonlinear interactions between tides and planetary waves. In particular, modulation of tidal amplitude at the period of a 
planetary wave may result from non-linear mixing generating secondary waves, which then beat with the tide (Teitelbaum and Vial, 1991). Examples include interaction between the 12-h $\mathrm{S}_{2}$ solar tide and the quasi-2-day planetary wave (Mitchell et al., 1996; Palo et al., 1999). Here we should note that a simple beating between the 12.42- $\mathrm{h} \mathrm{M}_{2}$ lunar tide and the $12 \mathrm{~h} \mathrm{~S}$ solar tide will result in an apparent modulation of the $S_{2}$ tide at a period defined by the difference in frequency between the $\mathrm{M}_{2}$ and $\mathrm{S}_{2}$ tides (a frequency of $\sim 0.0677$ cycles per day, equivalent to a period of $\sim 14.8$ days). This latter period is close to that of the 16-day planetary wave and so may be mistakenly interpreted as resulting from a non-linear interaction between the 16-day planetary wave and the 12-h $\mathrm{S}_{2}$ solar tide (a point noted by Stening et al., 1997b; Pancheva et al., 2002). Care must therefore be taken in attributing apparent fluctuations of the $12-\mathrm{h} \mathrm{S}_{2}$ solar tide at a period near the 16 day wave to interaction with the 16-day wave.

We may therefore ask the question, does the lunar tide detected in the meteor radar data presented here actually arise from an interaction between the 16-day wave and the solar 12-h tide? We are confident that we have identified a genuine lunar tidal signal for the following two reasons. Firstly, the observed monthly-mean lunar tidal phases are consistent from year to year. This would not be so if the apparent lunar tide was actually being produced by interaction between the 12-h solar tide and 16-day planetary wave, because the planetary wave is randomly phased and so would produce a randomly phased apparent lunar tide. Secondly, the 16-day wave actually displays a range of periods near 16 days (e.g. Mitchell et al., 1999; Luo et al., 2002) and so any generation of an apparent lunar tide would actually result in a rather broad spectral peak near lunar tidal frequencies. However the periodogram of Fig. 1a reveals a very sharp peak at lunar tidal frequencies. We therefore conclude that the analysis presented here has detected a genuine lunar tidal signal in the data.

\section{Conclusion}

Two meteor radars have been used to measure the lunar $\mathrm{M}_{2}$ tide at $\operatorname{mid}\left(\mathrm{UK}, 52^{\circ} \mathrm{N}\right)$ and arctic latitudes (Esrange, $68^{\circ} \mathrm{N}$ ). The observations over the UK comprise the longest study of the lunar tide in the MLT region to date, covering an interval of 16 years. The observations of the lunar tide at Esrange make up the longest continuous data set at Arctic latitudes and are currently the most northerly study of the lunar tide.

At both locations the lunar tidal amplitudes were found to be largest in winter (up to $11 \mathrm{~ms}^{-1}$ ), with a secondary maximum in autumn. Data from Esrange shows the amplitudes increase with height between 78 and $98 \mathrm{~km}$. Generally larger amplitudes were found over Esrange than over the UK, which is surprising due to the latitudinal structure expected from the Hough modes. Annual-mean amplitudes from the UK data set show that the $\mathrm{M}_{2}$ lunar tide exhibits significant year-toyear variability.

The zonal and meridional phases observed over both locations are in quadrature, with the meridional component leading the zonal component. As both components have similar amplitudes this indicates that the tide is circularly polarised and rotating clockwise viewed from above. For the northern hemisphere this indicates that the lunar $\mathrm{M}_{2}$ tide is propagating upward.

Over the UK, results from the Vial and Forbes (1994) model resolved the seasonal structure very well, but predicted the amplitudes to be approximately a factor of 2 larger than those observed. This is most likely due to the rapid increase in amplitude with height. The seasonal pattern in phases also fits very well with that observed, but there is a systematic offset of $\sim 2$ lunar hours.

The results from Collm (Stening and Jacobi, 2001) show a very good agreement with the amplitudes, but an approximately 2 lunar hour phase difference, most likely due to uncertainty in height using the LF D1 method. The data from Saskatoon (Stening et al., 1994) show the same seasonal behaviour, however, the amplitudes were $\sim 50 \%$ larger. This difference in amplitude can be explained by the difference in height of the measurements. The Saskatoon observations were made at a higher altitude than those of the UK. Comparisons of the phases between these sites show very good agreement.

For Arctic latitudes, the Vial and Forbes (1994) model amplitudes agree very well with the observations presented here. However, the observations reveal smaller amplitudes than predicted by the model in autumn and early winter. The model reproduces the phase behaviour very well.

Vertical wavelengths measured in the Arctic range from $15 \mathrm{~km}$ in March to $63 \mathrm{~km}$ in January. This disagrees with the models vertical wavelengths during summer, where much longer wavelengths are predicted. Note that this is where the errors on the phases are at their highest.

Comparisons with observations from Poker Flat (Stening et al., 1990) show reasonable agreement in the amplitudes to those observed over Esrange. The phases agree during September to December, but in the majority of other months phases are in anti-phase to those over Esrange, which could reflect the presence of non-migrating lunar tidal modes.

A long term average of Poker Flat data (1980-1984) shows a long vertical wavelength in July, but in a single year's data, the vertical wavelength is shown to be much shorter and more in agreement with that seen over Esrange. This may be due to the fact that the tide exhibits a high degree of interannual variability.

The seasonal variation of amplitude and phase seen in the tide over both locations has been found to be very similar to that seen in the $S_{2}$ solar semi-diurnal tide, including the very abrupt autumnal equinox enhancement in amplitude.

As a final note of caution, a beating between the solar $\mathrm{S}_{2}$ and the lunar $\mathrm{M}_{2}$ tides could produce an apparent modulation 
of the $\mathrm{S}_{2}$ tide at periods near 16 days. This could be misinterpreted as a non-linear interaction between the 16-day planetary wave and the solar $\mathrm{S}_{2}$ tide.

Acknowledgements. Model data of the Vial and Forbes Lunar tidal model was kindly supplied via the CEDAR database.

Edited by: F.-J. Lübken

\section{References}

Beldon, C. L., Muller, H. G., and Mitchell, N. J.: The 8-hour tide in the mesosphere and lower thermosphere over the UK, 19882004, J. Atmos. Sol.-Terr. Phys., 68, 655-668, 2006.

Chapman, S. and Lindzen R. S.: Atmospheric Tides: Thermal and Gravitational, 201 pp., D. Reidel Publishing Company Dorderecht - Holland, 1970.

Luo, Y., Manson, A. H., Meek, C. E., Thayaparan, T., MacDougall, J., and Hocking, W. K.: The 16-day wave in the mesosphere and lower thermosphere: simultaneous observations at Saskatoon (52 degrees N, 107 degrees W) and London (43 degrees N, 81 degrees W), Canada, J. Atmos. Sol.-Terr. Phys., 64, 1287-1307, 2002.

Malin, S. R. C. and Schlapp, D. M.: Geomagnetic Lunar Analysis by Least-Squares, Geophysical Journal of the Royal Astronomical Society, 60, 409-418, 1980.

Mitchell, N. J., Williams, P. J. S., Beard, A. G., Buesnel, G. R., and Muller, H. G.: Non-linear planetary tidal wave interactions in the lower thermosphere observed by meteor radar, Ann. Geophys.Atmospheres Hydrospheres And Space Sciences, 14, 364-366, 1996.

Mitchell, N. J., Middleton, H. R., Beard, A. G., Williams, P. J. S., and Muller, H. G.: The 16-day planetary wave in the mesosphere and lower thermosphere, Ann. Geophys.-Atmospheres Hydrospheres And Space Sciences, 17, 1447-1456, 1999.

Mitchell, N. J., Pancheva, D., Middleton, H. R., and Hagan, M. E.: Mean winds and tides in the Arctic mesosphere and lower thermosphere, J. Geophys. Res.-Space Phys., 107, 1004(A1), doi:10.1029/2001JA900127, 2002.

Muller, H. G., Havill, R. L., Comley, V. E., and Hill, P. C. J.: A Study Of Meteor Radar Winds From 2 Locations In The BritishIsles, J. Atmos. Terr. Phys., 57, 979-993, 1995.

Murphy, D.J., Tsutsumi, M., Riggin, D. M., Jones, G. O. L., Vincent, R. A., Hagan, M. E., and Avery, S. K.: Observations of a nonmigrating component of the semidiurnal tide over Antarctica, J. Geophys. Res., 108(D8), 4241, doi:10.1029/2002JD003077, 2003.

Palo, S. E., Roble, R. G., and Hagan, M. E.: Middle atmosphere effects of the quasi-two-day wave determined from a General Circulation Model, Earth Planets And Space, 51, 629-647, 1999.

Pancheva, D., Merzlyakov, E., Mitchell, N. J., Portnyagin, Y., Manson, A. H., Jacobi, C., Meek, C. E., Luo, Y., Clark, R. R., Hocking, W. K., MacDougall, J., Muller, H. G., Kurschner, D., Jones, G. O. L., Vincent, R. A., Reid, I. M., Singer, W., Igarashi, K., Fraser, G. I., Fahrutdinova, A. N., Stepanov, A. M., Poole, L. M. G., Maliga, S. B., Kashcheyev, B. L., and Oleynikov, A. N.: Global-scale tidal structure in the mesosphere and lower thermosphere during the PSMOS campaign of June-August 1999 and comparisons with the global-scale wave model, J. Atmos. Sol.Terr. Phys., 64, 1011-1035, 2002.

Riggin, D. M., Meyer, C. K., Fritts, D. C., Jarvis, M. J., Murayama, Y., Singer, W., Vincent, R. A., and Murphy, D. J.: MF radar observations of seasonal variability of semidiurnal motions in the mesosphere at high northern and southern latitudes, J. Atmos. Sol.-Terr. Phys., 65, 483-493, 2003.

Schlapp, D. M., Stening, R. J., Forbes, J. M., Manson, A. H., Meek, C. E., and Vincent, R. A.: N-2 and M(2) lunar tides: Atmospheric resonance revisited, Ann. Geophys.-Atmos. Hydrospheres Space Sci., 14, 826-836, 1996.

Smith, A. K., Pancheva, D. V., and Mitchell, N. J.: Observations and modelling of the 6-hour tide in the upper mesosphere, J. Geophys. Res.-Atmos., 109, D10105, doi:10.1029/2003JD004421, 2004.

Stening, R. J., Meek, C. E., and Manson, A. H.: Lunar Tidal Winds Measured In The Upper-Atmosphere (78-105 km) At Saskatoon, Canada, J. Atmos. Sci., 44, 1143-1151, 1987.

Stening, R. J. and Vincent, R. A.: A Measurement Of Lunar Tides In The Mesosphere At Adelaide, South-Australia, J. Geophys. Res-Space Phys., 94, 10 121-10 129, 1989.

Stening, R. J., Avery, S. K., and Tetenbaum, D.: Observations Of Lunar Tides In Upper-Atmosphere Winds At Poker Flat, Alaska, J. Atmos. Terr. Phys., 52, 715-721, 1990.

Stening, R. J., Manson, A. H., Meek, C. E., and Vincent, R. A.: Lunar Tidal Winds At Adelaide And Saskatoon At 80 To $100 \mathrm{~km}$ Heights - 1985-1990, J. Geophys. Res-Space Phys., 99, $13273-$ $13280,1994$.

Stening, R. J., Forbes, J. M., Hagan, M. E., and Richmond, A. D.: Experiments with a lunar atmospheric tidal model, J. Geophys. Res.-Atmos., 102, 13 465-13 471, 1997a.

Stening, R. J., Schlapp, D. M., and Vincent, R. A.: Lunar tides in the mesosphere over Christmas Island (2 degrees N, 203 degrees E), J. Geophys. Res.-Atmos., 102, 26 239-26 245, 1997 b.

Stening, R. J. and Jacobi, C.: Lunar tidal winds in the upper atmosphere over Collm, Ann. Geophys.-Atmos. Hydrospheres Space Sci., 18, 1645-1650, 2001.

Stening, R. J., Tsuda, T., and Nakamura, T.: Lunar tidal winds in the upper atmosphere over Jakarta, J. Geophys. Res-Space Phys., 108(A5), 1192, doi:10.1029/2002JA009528, 2003.

Teitelbaum, H. and Vial, F.: On Tidal Variability Induced by Nonlinear Interaction With Planetary Waves, J. Geophys. Res-Space Phys., 96, 14 169-14 178, 1991.

Tsuda, T., Tanii, J., Aso, T., and Kato, S.: Lunar Tides At Meteor Heights, Geophys. Res. Lett., 8, 191-194, 1981.

Vial, F. and Forbes, J. M.: Monthly Simulations Of The Lunar Semi-Diurnal Tide, J. Atmos. Terr. Phys., 56, 1591-1607, 1994.

Winch, D. E. and Cunningham, R. A.: Lunar Magnetic Tides at Watheroo: Seasonal, Elliptic, Evectional, Variational and Nodal, J. Geomagnetism and Geoelectricity, 24, 381-414, 1972.

Younger, P. T., Pancheva, D., Middleton, H. R., and Mitchell, N. J.: The 8-hour tide in the Arctic mesosphere and lower thermosphere, J. Geophys. Res-Space Phys., 107(12A), 1420, doi:10.1029/2001JA005086, 2002. 